\title{
Antioxidant defense system in prostate adenocarcinoma and benign prostate hyperplasia of elderly patients
}

\author{
K. SZEWCZYK-GOLEC ${ }^{1,3, *}$, J. TYLOCH${ }^{2}$, J. CZUCZEJKO ${ }^{1}$ \\ ${ }^{1}$ Department of Biochemistry; ${ }^{2}$ Department of General, Oncologic and Pediatric Urology; ${ }^{3}$ The Chair of Medical Biology, Ludwik Rydygier Collegium \\ Medicum, Nicolaus Copernicus University, Bydgoszcz, Poland
}

${ }^{*}$ Correspondence: karosz@cm.umk.pl

Received March 26, 2014 / Accepted April 29, 2014

\begin{abstract}
Prostate adenocarcinoma (PC) and benign prostate hyperplasia (BPH) are age-related diseases. The augmented oxidative stress is suggested to play an important role in the pathogenesis of both mentioned prostate disorders. In the presented study the antioxidant defense system in PC and BPH patients has been evaluated. The study was carried out on 30 PC patients

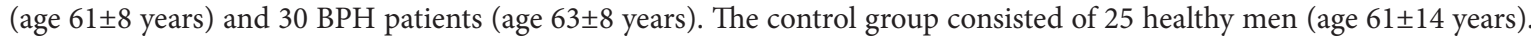
The reduced glutathione (GSH) concentrations in the erythrocytes and the activities of plasma superoxide dismutase (EC$\mathrm{SOD})$, plasma glutathione peroxidase (GPx-3), erythrocyte glutathione peroxidase (GPx-1) and erythrocyte glutathione S-transferase (GST) were measured in the examined groups. GSH concentrations in the erythrocytes and plasma GPx-3 activities in the PC group $(2.31 \pm 0.27 \mathrm{mmol} / \mathrm{l}$ and $186.2 \pm 39 \mathrm{U} / \mathrm{l}$, respectively) were significantly lower $(\mathrm{P}<0.05)$ as compared with the control group $(2.52 \pm 0.24$ and $211.8 \pm 26$, respectively) and the BPH group $(2.45 \pm 0.27$ and $206.6 \pm 48$, respectively). Erythrocyte GPx-1 activities in the BPH patients $(14.76 \pm 3.5 \mathrm{U} / \mathrm{g} \mathrm{Hb})$ were statistically decreased $(\mathrm{P}<0.05)$ than in the healthy people (16.94 \pm 3.7$)$ and in the PC patients (16.82 \pm 3.7$)$. There were no significant differences in the activities of GST and ECSOD between the PC group ( $2.72 \pm 1.34 \mathrm{nmol} \mathrm{CDNB}-\mathrm{GSH} / \mathrm{mg} \mathrm{Hb} / \mathrm{min}$ and $19.33 \pm 4.4 \mathrm{U} / \mathrm{ml}$, respectively), the BPH group $(2.53 \pm 1.00$ and $19.22 \pm 4.8$, respectively) and the controls ( $2.88 \pm 0.82$ and $19.40 \pm 4.1$, respectively). These results indicate that antioxidant defense system is decreased in the elderly patients with PC and BPH. The differences in the antioxidative system between examined groups of patients may suggest the different etiologies of both diseases.
\end{abstract}

Key words: antioxidative enzymes, antioxidant defense system, glutathione, benign prostate hyperplasia, prostate adenocarcinoma

The constant increase of life expentance has been observed since the beginning of 20th century, especially in developed countries. As a result, the population of people over 65 has been constantly growing, and consequently, the morbidity of agerelated chronic diseases has been increasing during last decades. Prostate diseases, that affect urinary and sexual functions, are the common problem for men over 50. Age is a main risk factor in case of the most commonly reported two prostate problems: benign prostate hyperplasia (BPH) and prostate adenocarcinoma (PC) $[1,2,3]$. BPH affects $20 \%$ of men in age of 40 and $70 \%$ of

\footnotetext{
Abbreviations: $\mathrm{BPH}$, benign prostate hyperplasia; CAT, catalase; EC-SOD, extracellular superoxide dismutase; $\mathrm{GPx}-1$, cytosolic glutathione peroxidase; $\mathrm{GPx}-3$, extracellular glutathione peroxidase; GSH, reduced glutathione; GST, glutathione S-transferase; PC, prostate adenocarcinoma; ROS, reactive oxygen species
}

men over 60 [3]. PC is the third most common diagnosed cancer in men around the world - it gives $10.2 \%$ of new cancer cases every year, $16.6 \%$ of that in developed countries [4]. $78 \%$ of new PC cases affect men in age over 65 [4]. In Poland in 2010, PC was the second frequently registered type of cancer $(13.2 \%)$ and the third cause of cancer death (7.6\%) among males [5].

The impaired redox homeostasis leading to the augmentation of oxidative stress is related to ageing process. Reactive oxygen species (ROS) are considered to play an important role in the pathogenesis of age-related diseases, as well as the carcinogenesis $[6,7,8]$. ROS generated in excessive amounts react with protein, lipid and nucleic acid molecules. It leads to the irreversible cellular structure damage and the development of many pathological processes.

Antioxidant defense system in humans, which prevents or neutralizes the negative effects of ROS action, comprises 
of the antioxidative enzymes (mainly superoxide dismutases (SODs), catalase (CAT), glutathione peroxidases (GPxs) and glutathione S-transferases(GSTs)) and the low molecular weight antioxidants (such as reduced glutathione (GSH), ascorbic acid, tocopherols, $\beta$-carotene, melatonin). The activities of antioxidative enzymes, as well as the concentrations of the low molecular weight antioxidants may decrease during ageing, which favours the increase of oxidative stress [9]. Weakened antioxidant defense system has been observed in patients with cancer $[10,11]$.

Many studies indicate the important role of the augmented oxidative stress in prostate carcinogenesis [12, $13,14]$. Prostate gland is a hormone-dependent tissue; its development and proper functioning depend on high local levels of androgens $[12,15,16]$. The long-term exposure of prostate tissue to the excessive androgen levels is supposed to be associated with the development of $\mathrm{BPH}[3,12,16]$. The high concentrations of androgens are also considered to increase the risk of PC incidence [12, 13, 17]. Androgens belong to the factors that induce oxidative stress and modify the activities of antioxidative enzymes $[13,14]$. The augmentation of oxidative stress in prostatic cells may result in mutation in DNA sequence, leading to the dysregulation of cell growth and division, and consequently to the tumor development.

Additional factor, that increases oxidative stress in prostate, is inflammation of the gland. This process involves the large number of stimulated leukocytes, which are a strong source of ROS [12].

The involvement of pro- and antioxidative processes in the pathogenesis of PC and BPH is not fully understood [18]. The comparison of the changes in the antioxidant defense system in case of PC and BPH may be useful for better understanding the etiologies of these disorders and the relationships between them. The aim of the study was to estimate the capacity of antioxidant defense system in patients with PC and BPH, by measurement of GSH concentrations and the antioxidative enzyme activities in the blood of examined patients.

Table 1. The selected parameters of antioxidative defense system in the blood of prostate adenocarcinoma (PC) and benign prostate hyperplasia $(\mathrm{BPH})$ patients and in the control group.

\begin{tabular}{lccc}
\hline parameter & $\begin{array}{c}\text { control group } \\
\mathrm{n}=25\end{array}$ & $\begin{array}{c}\mathrm{PC} \\
\mathrm{n}=30\end{array}$ & $\begin{array}{c}\mathrm{BPH} \\
\mathrm{n}=30\end{array}$ \\
\hline GSH [mM] & $2.52 \pm 0.24$ & $2.31 \pm 0.27^{*}, \#$ & $2.45 \pm 0.27$ \\
GPx-1 [U/g Hb] & $16.94 \pm 3.7$ & $16.82 \pm 3.7^{\#}$ & $14.76 \pm 3.5^{*}$ \\
GPx-3 [U/L] & $211.8 \pm 26$ & $186.2 \pm 39^{*}$ & $206.6 \pm 48$ \\
GST [nmol CDNB- & $2.88 \pm 0.82$ & $2.72 \pm 1.34$ & $2.53 \pm 1,00$ \\
GSH/mg Hb/min.] & & & \\
EC-SOD [U/mL] & $19.40 \pm 4.1$ & $19.33 \pm 4.4$ & $19.22 \pm 4.8$ \\
\hline
\end{tabular}

${ }^{*} \mathrm{P}<0.05$ (PC or BPH patients vs control group)

${ }^{*} \mathrm{P}<0.05$ ( $\mathrm{PC}$ vs $\mathrm{BPH}$ patients)

\section{Materials and methods}

The study was carried out on 60 patients of Department of Urology in Collegium Medicum, Nicolaus Copernicus University, Bydgoszcz, Poland, scheduled for the radical prostatectomy: 30 patients with diagnosed PC (mean age 61 \pm 8 yrs) and 30 patients with BPH (mean age $63 \pm 8$ yrs). The control group consisted of 25 healthy male volunteers (mean age $61 \pm 14 \mathrm{yrs}$ ). The participants were evaluated by standard physical examination and routine clinical laboratory tests. People addicted to alcohol and/or tobacco, and patients with diabetes mellitus, ischaemic heart disease, a history of stroke, renal failure or other conditions of known free radical etiology were excluded from the study. All participants provided written consent to participate in the experiment, which was approved by the local ethics committee.

The blood samples were taken early in the morning after overnight fasting from the patients just before surgery and from the healthy men. The blood samples were collected from the cubital vein into heparinized tubes $(6 \mathrm{~mL})$ and then centrifuged (2500 $\mathrm{g}$ for 10 minutes). Plasma was separated and stored at $-80^{\circ} \mathrm{C}$, for further analysis. The hemolysate was prepared by three-fold freezing and thawing; the washed erythrocytes were suspended in bi-distilled water.

The concentration of erythrocyte GSH was measured using the Beutler method [19]. The activities of extracellular superoxide dismutase (EC-SOD, E.C.1.15.1.1) and extracellular glutathione peroxidase (GPx-3; E.C.1.11.1.9) were determined in the plasma by the methods of Paoletti and Mocali [20], and Paglia and Valentine [21], respectively. The erythrocyte activities of cellular glutathione peroxidase $(\mathrm{GPx}-1)$ and glutathione S-transferase (GST, E.C.2.5.1.18) were assayed in the hemolysate according to the method of Paglia and Valentine [21], and Habig et al. [22], respectively. The hemoglobin concentration in hemolysate was estimated after conversion into cyanmethemoglobin form using a commercial reagent (Biomed, Poland).

All results were expressed as mean \pm S.E.M. The one-way analysis of the variance followed by the Tukey post hoc test was performed to determine the statistical significance of differences. The level of significance was set at $\mathrm{P}<0.05$.

\section{Results}

All results of the measured oxidative stress parameters are shown in Table 1. There were no significant differences in the erythrocyte GSH levels and the plasma GPx-3 activities between the BPH and control groups. Both the GSH concentrations and the plasma GPx-3 activities were significantly lower in the PC patients when compared with the healthy persons $(\mathrm{P}<0.05)$, as well as with the $\mathrm{BPH}$ patients $(\mathrm{P}<0.05)$. However, the erythrocyte GPx-1 activities were similar in the $\mathrm{PC}$ and control groups, but decreased statistically in the BPH group $(\mathrm{P}<0.05)$. There were no significant differences in the 
activities of erythrocyte GST and plasma EC-SOD between the PC, BPH and control groups.

\section{Discussion}

The weakened activity of antioxidative system in the blood of elderly BPH an PC patients was demonstrated in the presented study. The impaired antioxidant defense system in ageing organism may not be able to counteract the intensified ROS synthesis, leading to the oxidative-induced damage of cellular structures and the pathological changes. It was found that the significant augmentation of oxidative stress accompanied the ageing process within the prostate tissue $[17,23]$. The adverse changes in the pro- and antioxidative system in the blood of patients with prostate diseases were also observed $[24,25]$. The augmented oxidative stress may be due to the overproduction of free radicals or the decrease in the activities of antioxidative enzymes, as well as the lowmolecular antioxidant levels.

In the presented study the significant lower GSH concentrations in the erythrocytes of the PC patients in comparison with the healthy men and the BPH patients were observed. GSH is an intracellular tripeptide, that exerts many biological functions, including the cell protection against the free radical action. GSH serves as a main electron donor in the reactions catalyzed by glutathione peroxidases. The concentration of GSH in erythrocytes, which are especially exposed on the free radical effects, is supposed to be an appropriate indicator of GSH level in the organism $[26,27]$. The decreased concentrations of GSH during ageing of human organism were observed [27]. Interestingly, the inhibitory effect of dietary glutathione supplementation on the oral cancerogenesis in rats was demonstrated [28]. Similarly to the presented study, Doğru-Abbasoğru et al. [24] also observed the decreased content of sulfhydryl groups in plasma of PC patients when compared with $\mathrm{BPH}$ patients. The observed GSH depletion in the PC patients may reflect its intracellular oxidation in the augmented oxidative stress condition.

There were the significant lower activities of plasma GPx-3 in the PC group and the statistically decreased activities of erythrocyte GPx-1 in the BPH patients in the presented study. GPxs catalyze the reduction of hydrogen peroxide and other organic hydroperoxides to water and corresponding alcohols, and thus take a part in the defense of organism against ROS action. GPx-1 seems to be involved in the antioxidative protection of organism in the condition of oxidative stress, when the additional factors increasing the stress are present [29]. The highest activity of this enzyme is observed in the liver and erythrocytes [30]. However, GPx-3 acts as a main reductor of hydroperoxides in plasma [31]. Some authors demonstrated the decreases of GPx activities in plasma or erythrocytes of cancer patients [25], whereas the others did not observe any significant differences in GPx-3 activities between patients with cancer and healthy people [32]. Yilmaz et al. [25] and Ahmed et al. [33] observed the most decreased activities of GPx-1 in the erythrocytes of BPH patients. In the study performed by Yilmaz et al. [25] the erythrocyte GPx-1 activities in PC patients were also lower than in healthy men. There were no differences in the erythrocyte and plasma GPx activities between PC and BPH patients in some other studies [24, 34]. GPxs are selenoenzymes. The observed decreases of GPxs might be associated with Se deficit in the diet of the elderly subjects. The other possible explanation may be the oxidative modification of proteins caused by ROS [35].

A very intringuing experiment was performed by Luchman et al. [36] to explicate the possible role of selenoproteins in the prostate carcinogenesis. In this experiment, the expression of the selenoproteins in mouse prostatic epithelium was reduced by deletion of a selenocysteine-tRNA gene. That resulted in the development of the prostatic intraepithelial neoplasia lesion. Moreover, the increases in lipid peroxidation markers in the gene-deficient epithelial cells were also found.

There were no differences in the EC-SOD and GST activities between the PC, BPH and control groups in the presented study. SODs act as the first step of antioxidative defense of organism, catalyzing the dismutation of superoxide anion into molecular oxygen and hydrogen peroxide, which is less harmful for cells. GSTs are a family of isoenzymes involved in the metabolism of xenobiotics including cancerogens [37]. GSTs catalyze the reactions of GSH conjugation to many electrophilic substrates for the purpose of their detoxification. Doğru-Abbasoğru et al. [24] noticed no differences in the plasma SOD activities between PC and BPH patients. However, Yilmaz et al. [25] observed the decreased activities of SOD in the erythrocytes of PC and BPH patients when compared with healthy men. Similarly, Ahmed et al. [33] found the decreased plasma activities of SOD and GST in BPH group. The observed lack of alterations in the EC-SOD and GST activities in the PC and the BPH patients may suggest that the increased ROS generation plays a more important role in the prostate pathogenic processes than weakened antixidant defense system.

$\mathrm{BPH}$ is known as a factor increasing the risk of PC [38], nevertheless the relations between these conditions are still controversial. According to some authors $\mathrm{BPH}$ may represent the precancerous condition [39]. However, it should be taken into account, that $\mathrm{BPH}$ develops in the transition zone of the prostate, whereas PC arises predominantly in the peripheral zone of the gland. Considering the different origin, some other authors suggest that there is not causal relationship between $\mathrm{BPH}$ and $\mathrm{PC}$, but that they occur in parallel during the ageing of prostate tissue [40]. The differences in the GSH concentrations and the GPx activities of the PC and BPH patients observed in the presented study does not support the causal link between both prostate disorders.

Undoubtedly, the weakened antioxidant defense system observed in the blood of elderly patients with PC or BPH points that the augmented oxidative stress is involved in the development of both pathological prostate conditions. 
However, the distinct patterns of these changes found in the examined groups of patients suggest the different etiologies and lack of causal relationship between $\mathrm{PC}$ and $\mathrm{BPH}$.

\section{References}

[1] BOROWKA A Epidemiology of the prostate carcinoma in Poland. Urol Pol 1999; 52: 1-6.

[2] SCHULMAN C, LUNENFELD B The ageing male. World J Urol 2002; 20: 4-10. http://dx.doi.org/10.1007/s00345-002$\underline{0258-3}$

[3] UNTERGASSER G, MADERSBACHER S, BERGER P Benign prostatic hyperplasia: age-related tissue-remodeling. Exp Gerontol 2005; 40: 121-128. http://dx.doi.org/10.1016/j. exger.2004.12.008

[4] PARKIN DM Global statistics in the year 2000. Lancet Oncol 2001; 2: 533-543. http://dx.doi.org/10.1016/S14702045(01)00486-7

[5] WOJCIECHOWSKA U, DIDKOWSKA J, ZATONSKI W, EDITORS. Cancer in Poland 2010. Warsaw: Centrum Onkologii - Instytut im. M. Skłodowskiej-Curie, 2012.

[6] MCCORD JM The evolution of free radicals and oxidative stress. Am J Med 2000; 108: 652-659. http://dx.doi. org/10.1016/S0002-9343(00)00412-5

[7] OLDHAM KM, BOWEN PE OXIDATIVE STRESS IN CRITICAL CARE: Is antioxidant supplementation beneficial? J Am Diet Assoc 1998; 98: 1001-1008. http://dx.doi.org/10.1016/ S0002-8223(98)00230-2

[8] YU BP Cellular defenses against damage from reactive oxygen species. Physiol Rev 1994; 74: 139-162.

[9] KEDZIORA-KORNATOWSKA K, CZUCZEJKO J, PAWLUK H, KORNATOWSKI T, MOTYL J et al. The markers of oxidative stress and activity of the antioxidant system in the blood of elderly patients with essential arterial hypertension. Cell Mol Biol Lett 2004; 9: 635-641.

[10] SUN Y Free radicals, antioxidant enzymes, and carcinogenesis. Free Radic Biol Med 1990; 8: 583-599. http://dx.doi. org/10.1016/0891-5849(90)90156-D

[11] WARNER HR Superoxide dismutase, aging, and degenerative disease. Free Radic Biol Med 1994; 17: 249-258. http://dx.doi. org/10.1016/0891-5849(94)90080-9

[12] COMHAIRE F, MAHMOUD A Preventing diseases of the prostate in the elderly using hormones and nutriceuticals. Aging Male 2004; 7: 155-169. http://dx.doi.org/10.1080/136 85530412331284722

[13] RIPPLE MO, HENRY WF, SCHWARZE SR, WILDING G, WEINDRUCH R Effect of antioxidants on androgen-induced AP-1 nad NF-(KappaB) DNA-binding activity in prostate carcinoma cells. J Natl Cancer Inst 1999; 91: 1227-1232. http:// dx.doi.org/10.1093/jnci/91.14.1227

[14] SIDDIQUI IA, RAISUDDIN S, SHUKLA Y Protective effects of black tea extract on testosterone induced oxidative damage in prostate. Cancer Lett 2005; 227: 125-132. http://dx.doi. org/10.1016/j.canlet.2004.10.046

[15] MARKER PC, DONJACOUR AA, DAHIYA R, CUNHA GR Hormonal, cellular, and molecular control of prostatic development. Dev Biol 2003; 253: 165-174. http://dx.doi. org/10.1016/S0012-1606(02)00031-3

[16] SCHALKEN JA The androgen cascade in ageing men: blessing or curse? Eur Urol Suppl 2003; 2: 8-12. http://dx.doi. org/10.1016/j.eursup.2003.09.009

[17] RIPPLE MO, HENRY WF, RAGO RP, WILDING G Prooxidant-antioxidant shift induced by androgen treatment of human prostate carcinoma cells. J Natl Cancer Inst 1997; 89: 40-48. http://dx.doi.org/10.1093/jnci/89.1.40

[18] PASCHOS A, PANDYA R, DUIVENVOORDEN WC, PINTHUS JH Oxidative stress in prostate cancer: changing research concepts towards a novel paradigm for prevention and and therapeutics. Prostate Cancer Prostatic Dis 2013; 16: 217-225. http://dx.doi.org/10.1038/pcan.2013.13

[19] BEUTLER E Red cell metabolism. In: Beutler E, editor. Red cell metabolism. A manual of biochemical methods. New York: Grune-Stratton, 1971: 103-105.

[20] PAOLETTI F, MOCALI A Determination of superoxide dismutase activity by purely chemical system based on NAD(P) H oxidation. Methods Enzymol 1990; 186: 209-220. http:// dx.doi.org/10.1016/0076-6879(90)86110-H

[21] Paglia DE, Valentine WN Studies on the quantitative and qualitative characterization of erythrocyte glutathione peroxidase. J Lab Clin Med 1967; 70: 158-169.

[22] Habig WH, Pabst MJ, JAKOBY WB Glutathione S-transferases. The first enzymatic step in mercapturic acid formation. J Biol Chem 1974; 249: 7130-7139.

[23] GHATAK S, HO SM Age-related changes in the activities of antioxidant enzymes and lipid peroxidation status in ventral and dorsolateral prostate lobes of noble rats. Biochem Biophys Res Commun 1996; 222: 362-367. http://dx.doi.org/10.1006/ $\underline{\text { bbrc. } 1996.0749}$

[24] DOGRU-ABBASOGLU S, AYKAC-TOKER G, KOCAK T, UNLUER E, UYSAL M Antioxidant enzyme activities and lipid peroxides in the plasma of patients with benign prostatic hyperplasia or prostate cancer are not predictive. J Cancer Res Clin Oncol 1999; 125: 402-404. http://dx.doi.org/10.1007/ $\underline{\mathrm{s} 004320050293}$

[25] YILMAZ MI, SAGLAM K, SONMEZ A, GOK DE, BASAL $S$ et al. Antioxidant system activation in prostate cancer. Biol Trace Elem Res 2004; 98: 13-19. http://dx.doi.org/10.1385/ BTER:98:1:13

[26] DELLA ROVERE F, GRANATA A, SAIJA A, BROCCIO M, TOMAINO A et al. -SH groups and glutathione in cancer patient's blood. Anticancer Res 2000; 20: 1595-1598.

[27] RICHIE JP, SKOWRONSKI L, ABRAHAM P, LEUTZINGER Y Blood glutathione concentrations in a large-scale human study. Clin Chem 1996; 42: 64-70.

[28] TRICKLER D, SHKLAR G, SCHWARTZ J Inhibition of oral carcinogenesis by glutathione. Nutr Cancer 1993; 20: 139-144. http://dx.doi.org/10.1080/01635589309514280

[29] CHENG WH, HO YS, VALENTINE BA, ROSS DA, COMBS GR JR et al. Cellular glutathione peroxidase is the mediator of body selenium to protect against paraquat lethality in transgenic mice. J Nutr 1998; 128: 1070-1076.

[30] BEILSTEIN MA, WHANGER PD Glutathione peroxidase activity and chemical forms of selenium in tissues of rats 
given selenite or selenomethionine. J Inorg Biochem 1988; 33: 31-46. http://dx.doi.org/10.1016/0162-0134(88)80032-1

[31] BJORNSTEDT M, XUE J, HUANG W, AKESSON B, HOLMGREN A The thioredoxin and glutaredoxin systems are efficient electron donors to human plasma glutathione peroxidase. J Biol Chem 1994; 269: 29382-29384.

[32] AKESSON B, STEEN B Plasma selenium and glutathione peroxidase in relation to cancer, angina pectoris and short-term mortality in 68-year-old men. Compr Gerontol 1987; 1: 61-64.

[33 AHMAD M, SUHAIL N, MANSOOR T, BANU N, AHMAD S Evaluation of oxidative stress and DNA damage in benign prostatic hyperplasia patients and comparison with controls. Ind J Clin Biochem 2012; 27: 385-388. http://dx.doi.org/10.1007/ s12291-012-0229-4

[34 HARDELL L, DEGERMAN A, TOMIC R et al. Levels of selenium in plasma and glutathione peroxidase in erythrocytes in patients with prostate cancer or benign hyperplasia. Eur J Cancer Prev 1995; 4: 91-95. http://dx.doi. org/10.1097/00008469-199502000-00009

[35 SOHAL RS Role of oxidative stress and protein oxidation in the aging process. Free Radic Biol Med 2002; 33: 37-44.
[36 LUCHMAN HA, VILLEMAIRE ML, BISMAR TA, CARLSON BA, JIRIK FR Prostate epithelium-specific deletion of the selenocysteine tRNA gene, Trsp, leads to early onset intraepithelial neoplasia. Am J Pathol 2014; 184: 871-877. http://dx.doi.org/10.1016/j.ajpath.2013.11.025

[37 HAYES PC, BOUCHIER IA, BECKETT GJ Glutathione Stransferase in humans in health and disease. Gut 1991; 32: 813-818. http://dx.doi.org/10.1136/gut.32.7.813

[38] BOYLE P, ZARIDZE DG Risk factors for prostate and testicular cancer. Eur J Cancer 1993; 29A: 1048-1055. http://dx.doi. org/10.1016/S0959-8049(05)80222-9

[39] OLINSKI R, ZASTAWNY TH, FOKSINSKI M, BARECKI A, DIZDAROGLU M DNA base modifications and antioxidant enzyme activities in human benign prostatic hyperplasia. Free Radic Biol Med 1995; 18: 807-813. http://dx.doi. org/10.1016/0891-5849(94)00171-F

[40] DE MARZO AM, COFFEY DS, NELSON WG New concepts in tissue specificity for prostate cancer and benign prostatic hyperplasia. Urology 1999; 53:29-39. http://dx.doi.org/10.1016/ $\underline{\text { S0090-4295(98)00536-6 }}$ 